https://doi.org/10.31713/m1116

\title{
ELECTRIC TREATMENT AND REGULATION OF BIOTOXIC PROPERTIES OF DRILLING WATERS
}

\author{
Berezutskyi V.V. \\ National Technical University "Kharkiv Polytechnic Institute", \\ Head of the Department "Labor \& Environment safety" \\ Doctor of Technical Science, Professor, Ukraine \\ Berezutska N.L. \\ Kharkiv National University of Radio Electronics \\ Department of Occupational Safety \\ $\mathrm{PhD}$, Associate Professor, Ukraine \\ Khalil V.V. \\ O. M. Beketov National University of Urban Economy in Kharkiv, \\ Department of Labour Protection and Safety, \\ $\mathrm{PhD}$, Associate Professor, Ukraine \\ Ilinska O.I. \\ National Technical University "Kharkiv Polytechnic Institute" \\ Department "Labor \& Environment safety", \\ $\mathrm{PhD}$, Associate Professor, Ukraine
}

\begin{abstract}
Well drilling is accompanied by the formation of significant volumes of water that contain mechanical and biological impurities. The purpose of the work is to investigate the possibility of regulating the biological properties of drilling and other types of water that using the technologies of electrical processing (electrooxidation). The analysis of methods and technologies for the disinfection of aqueous solutions and emulsions is carried out. The process of electrooxidation of bacteria in contact with the surface of the electrode plates is considered. The determination of the electrokinetic charge of the surface of particles (bacteria) is carried out, which must be taken into account when calculating the processes and equipment for the electrooxidation of bacteria in technological aqueous solutions such as emulsions. The processes of electrooxidation of aqueous emulsions such as Ukrinol and Triethanolamine which are widely used in cutting, grinding, etc., are considered. Physical and mathematical models of disinfection processes at different values of electric current and surface area of oxidizing electrodes are studied. The factors influencing the disinfection process have been determined. Conceptual approaches to the creation of electrooxidizing devices for the disinfection of emulsions directly in the channels through which aqueous technological solutions move are proposed. Aspects of practical application of electrooxidation technology are considered.
\end{abstract}

Keywords: drilling water, emulsions, bacteria, micelles, surface charge, electrodes. 


\section{Introduction}

Among the problems of drilling wells is the environmental pollution from of drilling water. The drilling process uses drilling fluids and generates waste fluids and cuttings. The drilling fluids that used in drilling operations are including water based drilling fluids (WBF), oil based fluids (OBF) and synthetic based fluids (SBF). The wastes generated in the largest volumes during drilling oil and gas wells are drilling fluids and cuttings. There are several options to manage drilling wastes: discharge, down-hole injection and onshore disposal. In many regions of the world, some types of drilling fluids and drill cuttings may be discharged to the sea if they meet certain environmental requirements. Drilling fluids have operational properties that including cooling and lubricating.

Practically all technological operations of cutting, grinding, washing are accompanied by the use of aqueous solutions, that need for their subsequent storage, cleaning and disposal. The search of extending the use of each cubic meter of such a solution leads are need to develop chemical bactericidal additives or other drugs that only block the development process for a while, and then it continues all the same, but the rate of growth in the number of bacteria increases. The only available and effective bactericidal treatment is the electrooxidation of bacterial cells on the surface or in the electrode area. Such an oxidation process is achieved in electrolyzers (flow-through and non-flow-through) or by means of electrode units, which are placed directly in the channel along which the aqueous process medium moves. The choice of one or another method is determined by the volumes of water technological environments, their properties and the economic possibilities of the enterprise.

This article discusses the theoretical foundations for regulating the biotoxic properties of drilling fluids that had formulated on the basis of laboratory research.

\section{Literature review}

The article [1] affects issues of pollution concerns of water in developing countries and categorised in terms of physical, chemical and biological pollutants such as turbidity, organic matter and bacteria. The processes are involved in removing the contaminants are including physical processes such as sedimentation, filtration such as 
slow-sand filtration, coagulation and flocculation, and disinfectant processes such as chlorination reviewed.

Chemical methods of processing technical emulsions are widely was used in the production. But microorganisms adapt to them, and the cost of such additives is growing up every year. Besides, another article [2] states that chlorination is the most widely used method for disinfecting water, that supplies in the United States. However, the discovery of chlorination's can result in the formation of trihalomethanes (THM's) and other halogenated hydrocarbons has prompted the reexamination of available disinfection methodology with goal of determine alternative agents or procedures.

In article of author [3] suggests solar disinfection, or SODIS, refers the method of using sunlight to inactivate microbes in biologically contaminated water. The contaminated water is placed in transparent containers and it be exposed to strong sunlight for at least 6$8 \mathrm{~h}$. At the end of this solar exposure, the microbes, which could otherwise cause waterborne diseases, are inactivated and unable to cause illness. However, the use of this method for contaminated technical emulsions causes serious problems and is not effective enough.

In articale [4] says that the safe operation of water reuse depends on effluent disinfection. The authors of the article draw attention to the methods of electrochemical treatment of wastewater as a means for its disinfection. The electrochemical generation of chlorine dioxide from an un-buffered solution of sodium chlorite and sodium chloride mixture in an un-divided electrochemical cell under constant current mode, with a view to optimize various process parameters, has been studied, which have a direct bearing on the chlorine dioxide formation efficiency under laboratory conditions. However, in this case, the option of electrochemical dissolution of certain chemical compounds in order to obtain an oxidizing agent is considered, but not the oxidation process on the surface of the electrodes itself.

At this article [5] shown, that cutting fluids are widely used to ensure high production quality and process stability in machining processes. However, especially in case of water based cutting fluids microbial contamination leads to a reduced performance and thus, shortened service life. To control the growth of the microorganisms, biocides are used in practice. Biocides, however, can be toxic to humans and the use is officially regulated, whereby alternative disinfec- 
tion methods e.g. ultraviolet radiation or ozone are getting more in the focus.

In article [6] says that biocides can be toxic to humans and the use is officially regulated, whereby alternative disinfection methods e.g. ultraviolet radiation or ozone are getting more in the focus. It was mentioned in the article above, however, in terms of production, they are in no hurry to purchase expensive equipment.

At this article [7] talks about of metalworking fluids (MWF) that are mainly emulsions of oil in water containing additives such as corrosion inhibitors, emulsifiers, defoamers, and biocides. The future lies in the development of new molecules with biocidal activity corresponding to these ideal specifications, but in the meantime, it is possible to improve the performance of existing molecules currently on the market. As there is a diversity of the envelope structures of microorganisms and a diversity of molecular structures of biocides, each biocide presents its own inactivation mechanism and spectrum of activity.

In article [8] talks that some microbicides are suspected as being responsible for adverse health effects. Consequently, their usage has been restricted in recently adopted regulations. Given the limited number of microbicides currently approved for use in MWFs, alternative microbial contamination control strategies are needed. Makeup water whose content usually varies between 85 and $98 \%$ in the end use diluted MWF provides inorganic nutrients and a suitable growth habitat. Turbulent flow created by MWF recirculation at velocities of $\geq 0.8 \mathrm{~m}^{3} \mathrm{~min}^{-1}$ ( $\geq 200 \mathrm{gpm}$ ) creates an oxygenated environment for aerobic microbes.

This article [9] shows that there's two typical approaches for dealing with rejected MWFs are recovery and disposal, in which largely involve separation as the first essential step. The processes for separating MWFs emulsion are presented, including chemical coagulation, flotation, and electrocoagulation-flotation for their background and results from experiments. The effective separations with the highest efficiencies of $99 \%$ were attained from all conditions but at different operating time for electrocoagulation-flotation. The treatment rate was influenced by the condition for both electrode gap and current density. 
In article [10] authors say about of treatment of oil mist and miscellaneous oil. The removal mechanism and approach of microorganisms and the design principles of integrated recycling equipment are outlined. The scientific work [11] indicates the types of bacteria that were detected in both used MWF sump and mist samples. These included Ochrobactrum and Proprionibacterium at site visit one, and Methylobacterium at site visit two. Bacterial toxins in the form of "serinelike" proteases were detected within $76 \%$ of the MWF samples and in two of the mist samples. The study of bacteria species is very important for the development of disinfection technology. Work's conditions in production are not dangerous for the life and health of workers. However, if the coolant contains bacteria, this is become dangerous. In the article [12], the author points out that it is necessary to develop environmentally friendly fluids. But this is a difficult task because a lot of different specialists must take part.

In article [13] says that using of cutting fluids in machining processes is a serious concern because of their cost, and environmental and health effects. Reasons can be found in the excessive heat generated in the process, in the increase of the friction between the tool and the workpiece or in the necessity to evacuate the chips generated. The striving for sustainable products is also encouraging the developing of new cutting fluid formulations. In this paper, a comprehensive analysis of the use of cutting fluids and main alternatives in machining is carried out. Particularly, the analysis was done focusing on the economic, environmental and technical points.

The oil drilling industry is one of the most specific activities in the industrial world and, like any other industrial activity related to waste and the return of waste to the environment, connected with a planning to recycle, clean up and prevent long-term adverse consequences. It can have a long-term adverse effects for the climate [14].

In article [15] says that the main performance of problem with using of drilling water is as follows:

- pollution of surface water and groundwater;

- retention of heavy metals in soil, affecting plant growth and microbial reproduction, and at the same time due to plant absorption and enrichment, endangering human and animal health;

- salt and alkali in waste drilling fluid are very harmful to plant growth, even unable to grow, resulting in soil waste. 
The treatment methods of waste fluid generated during drilling are also constantly improving, from the original landfill method, incineration method and other methods to more environmentally friendly and harmless solid-liquid.

Separation method, demulsification method and other methods better protect the ecological environment of the ocean and land, and enable energy to be recycled and reused. However, no matter which kind of treatment method has a certain range of application, it should be selected reasonably. At the same time, in order to more effectively control the environmental pollution of waste drilling fluid, we should strengthen the source, control the process, and continue to develop more adaptable new technology.

The monograph [16] shows methods and technologies that allow to regulate the biotoxicity of drilling water and similar technological aqueous solutions. The such technologies are based on using of various devices, materials and devices based on electrochemical, gas and other methods of processing oil- and bio-containing waters. The most popular of them are electrochemical methods which are implemented in apparatuses (electrolyzers) with various types of electrodes and their arrangement in bloks. This allows to clean and decontaminate various aqueous process solutions and return them back for reuse.

However, there are many unresolved issues that require new research. One of these issues is the regulation of the ratio of the magnitude of the electric current relative to the flow rate of water, connected with the hardware design of the oxidation process of microorganisms directly in the channels through which water moves, and others.

\section{Research tasks}

- investigate the mobility of micelles in the interelectrode space,

- determine the possibility of using the method of electrooxidation of microorganisms for technical emulsions.

\section{Purpose}

to investigate the process of electrooxidation of microorganisms developing in the drilling and coolant water for example of lubricant coolants liquids.

\section{Research methodology}

The magnitude of the electric current flowing between the electrodes determines the speed of delivery of bacteria to the surface of 
the electrodes of oxidizers. This is especially important when disinfecting large volumes of aqueous media, since high linear velocity of fluid flows in the interelectrode space (between the electrodes) is limits the time of probable contact of bacteria with the oxidizing surface of the electrodes (contact time 1-5 s) [16].

Based on this, it is necessary to determine the $\zeta$ - potential of bacteria and their electrophoretic mobility in technological solutions such as lubricant coolants liquids (LCL) of a certain type. It is determined based on the fact that bacteria in aqueous media are located in between the micellar spaces and micelles formed by complexes of the type "water - oil - particles of pollution", "water - emulsifier oil", "oil - water", etc. By determining the electrophoretic velocity of the micelles, it is possible to determine the speed of their delivery to the surface of the oxidizing electrodes.

Measurements of the $\zeta$ - potential of micelles were carried out in accordance with the methodology and instrumentation equipment described in the literature $[17,18]$. The results of measurements and calculations are given in Table 1 . The applied voltage of $30 \mathrm{~V}$ corresponds to the voltage of an industrial rectifier of electric current.

Table 1

Values of $\zeta$-potential and electrophoretic velocity parameters micelles in MWFs

\begin{tabular}{c|c|c|c}
\hline $\begin{array}{c}\text { Characterization } \\
\text { of the coolant } \\
\text { micelles }\end{array}$ & $\begin{array}{c}\text { Linear velocity of } \\
\text { particles in an elec- } \\
\text { tric field, } \\
10^{-3} \mathrm{~m} / \mathrm{s}\end{array}$ & $\begin{array}{c}\text { Electrophoretic } \\
\text { speed, } \\
10^{-8} \mathrm{~m} / \mathrm{s}\end{array}$ & $\begin{array}{c}\zeta \text {-potential, } \\
\mathrm{mV}\end{array}$ \\
\hline Triethanolamine & 2,47 & 8,2 & 114 \\
\hline Ukrynol & 0,114 & 3,8 & 53 \\
\hline
\end{tabular}

From the results given in Table 1 seen that Triethanolamine can be disinfected more quickly because the mobility of its micelles is higher.

Microorganisms in the MWFs are mainly on the surface of emulsion micelles and in mud clots. Therefore, having determined the rate of movement of micelles between the electrodes during oxidation, it is possible to calculate the length of the plates for guaranteed contact of the particles with the surface of the oxidizing agent when they pass between the electrodes. 
Experimental installation. The experiment consisted in determining the influence of the size of the oxidation surface $(\mathrm{H})$ (the area of the electrode plates) on the efficiency of the oxidation process of bacteria. The material of the plates is stainless steel, the thickness $(D e)$ is $0.01 \mathrm{~m}$, the length $(L)$ is $0.052 \mathrm{~m}$. The volume of the processed liquid $(Q)$ is 0.21 . The vessel is a beaker with a diameter of $0.062 \mathrm{~m}$. Bacterial damage to the original liquid, according to the point system is equal to 4 points.

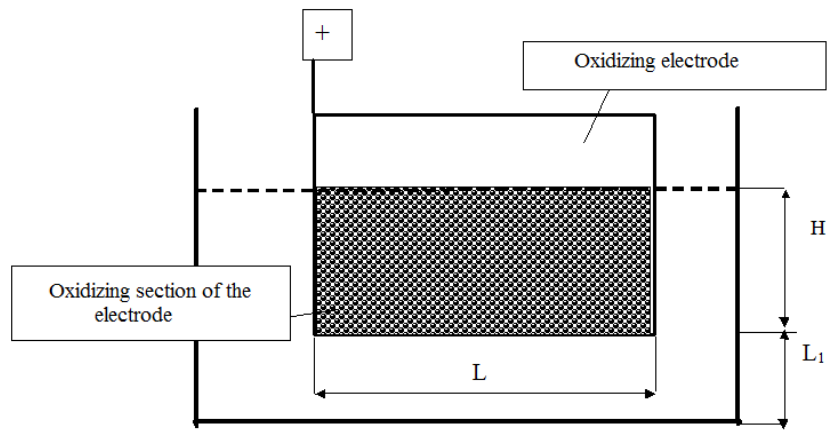

Fig. 1. Schematic of the experimental setup

To ensure the reliability of the experiment, the current value was kept constant, and the current density changed as a result of moving the electrodes in the beaker $(i=\mathrm{I} / \mathrm{S})$. The experimental results are shown in the Table 2. 
Table 2

Experimental parameters and results on bacterial oxidation on the surface of the oxidizing electrode

\begin{tabular}{c|c|c|c|c|c|c|c|c|c|c}
\hline \multirow{2}{*}{$o$} & \multicolumn{4}{|c|}{ Options } & \multicolumn{5}{c}{ Disinfection results, points } \\
\cline { 2 - 12 } & \multicolumn{4}{|c}{ Experiment } & \multicolumn{4}{c}{ Liquid processing time, s } \\
\hline & $L, M$ & $H, M$ & $i, A / \mathcal{M}^{2}$ & $L,, M$ & $I, A$ & 6 & 18 & 30 & 35 & 45 \\
\hline 1 & 0,052 & 0,01 & 961,5 & 0,055 & 0,5 & 3 & 4 & 4 & 4 & 4 \\
\hline 2 & 0,052 & 0,02 & 480,7 & 0,048 & 0,5 & 4 & 4 & 4 & 3,5 & 3 \\
\hline 3 & 0,052 & 0,03 & 320,5 & 0,035 & 0,5 & 3,5 & 3,5 & 3,5 & 3 & 3,5 \\
\hline 4 & 0,052 & 0,04 & 240,3 & 0,028 & 0,5 & 3 & 3 & 3 & 3 & 3 \\
\hline 5 & 0,052 & 0,05 & 192,2 & 0,015 & 0,5 & 3 & 3 & 2,5 & 2,5 & 1,5 \\
\hline
\end{tabular}

From the results shown in Table 2, we can conclude:

- the efficiency of the oxidation process on the surface of the electrode plates depends on the ratio of the volume of the liquid to be oxidized and the area of the electrode - oxidizer;

- the efficiency of oxidation processes is determined by the time of contact of the surface of the oxidizer plate with microorganisms.

These conclusions are confirmed by the curves in the Fig.2 and mathematical dependencies (1-5).

Dependence of electrooxidation of bacteria on the time of the process at different rates of electric current and oxidized surface shown in Fig. 2.

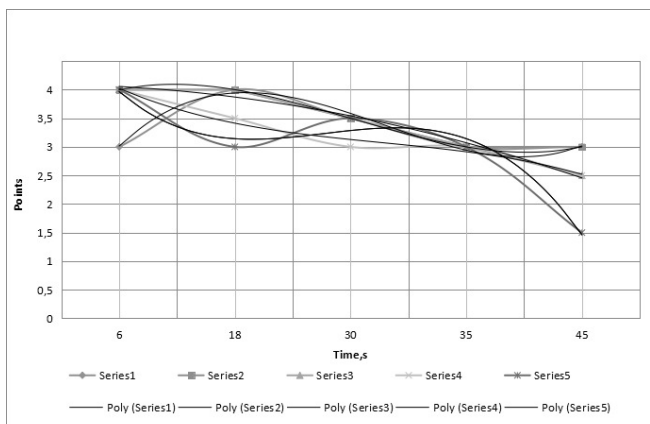

Fig. 2. Dependence of electrooxidation of bacteria on the time of the process at different rates of electric current and oxidized surface 
The resulting graphical curves (Fig. 2) are described by mathematical dependencies

$$
\text { series } 1, y=-0,208 x^{3}+1,732 x^{2}-4,5595 x+7 \text {, }
$$

by $R^{2}=0,974$

$$
\text { series } 2, y=0,0833 x^{3}-0,75 x^{2}+1,6667 x+3 \text {, }
$$

by $R^{2}=0,999$,

series $3, y=-0,071 x^{2}+0,0285 x+4,1$,

by $R^{2}=0,983$,

$$
\text { series } 4, y=-0,04166 x^{3}+0,41 x^{2}-1,5476 x+5,2 \text {, }
$$

by $R^{2}=0,975$,

$$
\text { series } 5, y=-0,2083 x^{3}+1,732 x^{2}-4,5595 x+7 \text {, }
$$
by $R^{2}=0,974$.

The obtained polyamial dependences make it possible to form a physical model of the process of electrooxidation of bacteria in a flow channel (pipe).

Description of the installation and process of disinfection. At Fig. 3 shows a diagram of a laboratory setup consisting of a collection tank for bacteria-infected drilling water (1), a valve for regulating the flow of disinfected water (2), electrode cells with metal plates made of insoluble metal $(3,4,5)$, a foam collection tank ( 6$)$, a container for collecting disinfected drilling water (7) and an electric current rectifier (9). Electrode cells 3,4,5, foam-collecting containers 6 and a container for collecting disinfected drilling water 7 are made of transparent organic glass, which allows you to visually observe the progress of the disinfection process and the hydrodynamics of flows. The disinfection process is carried out as follows: the drilling water affected by microorganisms from the container 1 through the valve 2 , with a previously set flow rate, is directed to the electrode cells 3 - 5 which are pre-filled with clean water or disinfected drilling water.

After that, the rectifier 9 is turned on, the set current value is set at 1-8 A. The disinfected drilling water is discharged through the foam collector 6 into the tank 7 .

If the process is carried out without foam separation and insufficient disinfection, a crust may form on the foam surface. After a day, swelling can be observed on the surface of the crust, which indicates the development of bacteria and the release of gases by them. The temperature of the medium varied within the range of $19-24{ }^{\circ} \mathrm{C}$. 




Fig. 3. Schematic of a laboratory electrooxidation plant of bacteria-infected drilling water

Laboratory tests have shown (Table 3) that at electric currents of up to $3 \mathrm{~A}$, disinfection is unsatisfactory, while a decrease in the number of bacteria is practically not observed, and an increase in the rate of their reproduction is characteristic.

Table 3

The results of laboratory studies on disinfection by electric current

\begin{tabular}{c|c|c}
\hline $\begin{array}{c}\text { Electric } \\
\text { current } \\
\text { strength, } \\
\text { A }\end{array}$ & $\begin{array}{c}\text { The degree of bacterio- } \\
\text { logical damage to water, } \\
\text { point }\end{array}$ & Visual observations \\
\hline 1 & IV & \multirow{2}{*}{$\begin{array}{c}\text { The original drilling water has IV } \\
\text { degree of bacterial lesion }\end{array}$} \\
\hline 2 & IV & \\
\hline 3 & III-IV & \\
\hline 4 & II & Abundant education \\
formation
\end{tabular}


With an electric current of 3-5 A, the drilling water is disinfected, however, after 2-3 days, an increase in the number of bacteria is observed. The reason for this may be: incomplete destruction of microorganisms; stationary storage - the liquid is stationary; bacteriological contamination of the storage tank. At a current of $5 \mathrm{~A}$, moderate foam release is observed (when disinfecting $1 \mathrm{~m}^{3}$ of water, $0.05 \mathrm{~m}^{3}$ $(50,1)$ of foam is released. An increase in the electric current of more than $5 \mathrm{~A}$ is accompanied by an abundant release of foam which worsens the disinfection process and significantly reduces the amount of disinfected emulsion. Given the large-scale transition, it should be recommended for industrial testing a current value in the range of 300-500 A.

In a laboratory facility, studies were carried out to disinfect cutting fluid in several cycles. One cycle of disinfection consists in passing the coolant through three series-connected electrode cells. Fig. 4 shows the results of cyclic disinfection of the coolant at a flow rate of $0.6 \mathrm{l} / \mathrm{min}$ and a current of $4.5 \mathrm{~A}$.

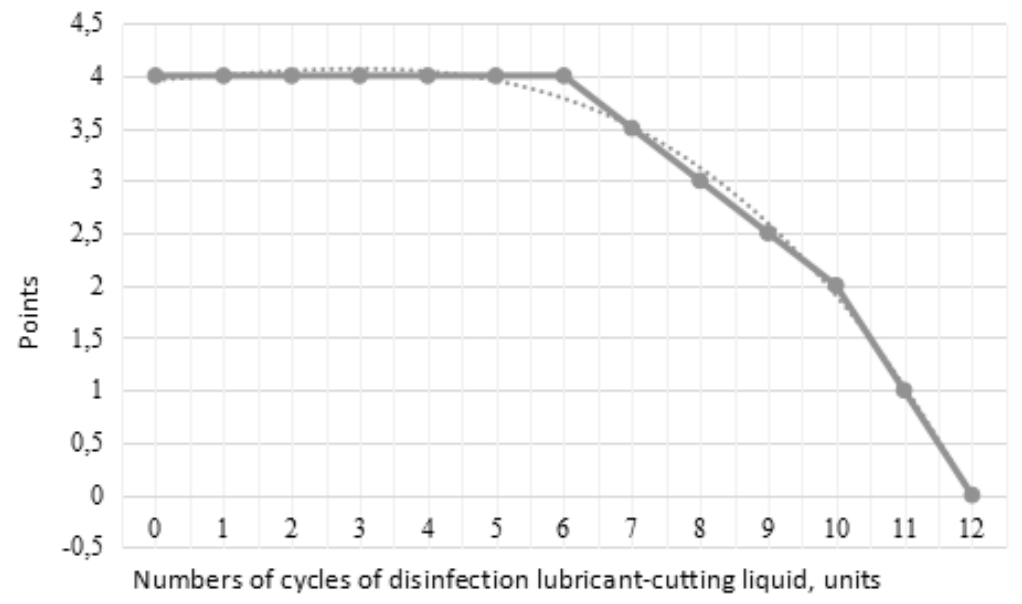

Fig. 4. Dependence of disinfection of cutting fluid on the number of cycles

The resulting graphical curves (Fig. 4) are described by mathematical dependencies by $R^{2}=0,996$.

$$
y=-0,0032 x^{3}+0,0169 x^{2}+0,0186 x+3,9266,
$$


It can be seen from the Fig. 3 that with 12-13 cycles of MWFs treatment, complete disinfection of the coolant occurs. The straight section on the line, characterizing the disinfection of the MWFs is determined by the time of decay of the coolant and the number of bacteria in it.

\section{Results}

Knowing the linear velocity of movement of micelles $\left(U_{m}\right)$ in an electric field, it is easy to determine the time for micelles to travel the distance between two electrodes that are at a distance one from another le $=0.01 \mathrm{~m}$ (the distance between the electrodes in industrial electrolyzers used to clean and disinfect water).

$$
t_{T}=\frac{l_{e}}{U m}=\frac{0,01}{0,114 \cdot 10^{-3}}=87 \mathrm{~s}
$$

$t_{T}$ is the time of passage of Triethanolamine micelles.

Similarly: $t_{U}=40.5=41 \mathrm{~s}$,

where $t_{U}$ is the time of passage of the Ukrynol type coolant micelles.

The development of bacteria disinfection equipment for production plants with a water flow rate of more than $100 \mathrm{~m}^{3} / \mathrm{h}$ was carried out on the basis of the following initial data: triethanolamine-based aqueous media; water consumption $-500 \mathrm{~m}^{3} / \mathrm{h}$; shop coolant storage capacity; the cross-sectional area is $1.2-5\left(\mathrm{~m}^{2}\right)$, the length of the tank is $10 \mathrm{~m}$. The sediment is deposited in the tank and is removed monthly from the bottom of the tank (1-2 tons).

Practical testing of the results of research in production has shown the promise of this area of research. It is necessary to take into account that an increase in current strength increases foam formation and can negatively affect the quality indicators of the MWFs. Therefore, it is necessary for each technical emulsion to select operating indicators for electric current.

The disadvantages of such oxidation of bacteria include the need to use electricity, but this is covered by the cost of purchasing, storing and using chemical additives of bactericides which are also harmful to workers and environment.

\section{Conclusions}

- the anodic oxidation of bacteria can be performed directly in the channels through which the flow of cutting fluid moves, with minimal structural changes to these channels; 
- the efficiency of the oxidation process on the surface of the electrode plates depends on the ratio of the volume of the liquid to be oxidized and the area of the electrode - oxidizer;

- the efficiency of oxidation processes is determined by the time of contact of the surface of the oxidizer plate with microorganisms;

- the decontamination effect depends on the optimal choice of the water flow rate and the magnitude of the electric current but the composition of the drill water is also of great importance. The presence of oils in the water complicates the process because oils cover the surface of the electrode plates and the oxidation process is inhibited.

References

1. Josephine Treacy. (2019). Drinking Water Treatment and Challenges in Developing Countries. Retrieved from https://www.intechopen.com/chapters/63707. DOI: 10.5772/intechopen.80780.

2. Drinking Water and Health: Volume 2. ISBN: 0-309-55406-3. Retrieved from https://www.ncbi.nlm.nih.gov/books/NBK234590/.

3. Javier Marugán. (2020). Solar Disinfection as a Water Treatment Technology / Javier Marugán, Stefanos Giannakis, Kevin G. McGuigan, Inmaculada Polo-López / DOI: https://doi.org/10.1007/978-3-319-70061-8_125-1.

4. Mohammad M. Amin. A review on wastewater disinfection / Mohammad M. Amin, Hassan Hashemi, Amir Mohammadi, Yung Tse Hung / International Journal of Environmental Health Engineering, 2013. No 2 (1): 1 - 9. DOI:10.4103/2277-9183.113209

5. Nadine Madanchia. Functional and Environmental Evaluation of Alternative Disinfection Methods for Cutting Fluids / Nadine Madanchia, Sebastian Thiedea, Christoph Herrmanna / The 24th CIRP CONFERENCE on Life Cycle Engineering, Volume 61, 2017. P. 558-563. DOI: https://doi.org/10.1016/j.procir.2016.11.175.

6. Yun-Hee Choi. Priority Setting for Management of Hazardous Biocides in Korea Using Chemical Ranking and Scoring Method / Yun-Hee Choi, Min-Sung Kang, Da-An Huh, Woo-Ri Chae, Kyong Whan Moon / International Journal of Environmental Research and Public Health, Mar 2020, No 17 (6). P. 1970. DOI: https://doi.org/10.3390/ijerph17061970 .

7. Patrick Di Martino. Ways to improve biocides for metalworking fluid / AIMS Microbiology, 2021, Volume 7, Issue 1: 13-27. DOI: https://doi.org/10.3934/microbiol.2021002 .

8. Frederick J. Passman, Peter Küenzi. Microbiology in Water-Miscible Metalworking Fluids / Tribology Transactions, Volume 63, 2020, Issue 6, P. 1147-1171. DOI: https://doi.org/10.1080/10402004.2020.1764684 . 
9. Nattawin Chawaloesphonsiya. Separation of Emulsified Metalworking Fluid by Destabilization and Flotation / Nattawin Chawaloesphonsiya, Nawadol Thongtaluang, Pisut Painmanakul / Scince and Technology Behind Nanoemulsions, 2018. DOI: 10.5772 /intechopen.75307

10. Wu X. Circulating purification of cutting fluid: an overview / Wu X, Li C, Zhou Z, Nie X, Chen Y, Zhang Y, Cao H, Liu B, Zhang N, Said Z, Debnath S, Jamil M, Ali HM, Sharma S / The International Journal, Advanced Manufacturing Technology, 26 Aug 2021, P. 1-36. DOI: https://doi.org/10.1007/s00170-02107854-1.

11. Jodi Brookes. Biological and chemical hazards in water-mix metalworking fluids and mists / Sheffield Hallam University, September 2017, 284 p. Retrieved from https://shura.shu.ac.uk/21507/1/Brookes_2017_PhD_BiologicalChemicalHazards.pdf .

12. Xifeng Wu. Circulating purification of cutting fluid: an overview / Xifeng Wu, Changhe Li, Zongming Zhou, Xiaolin Nie, Yun Chen, Yanbin Zhang, Huajun Cao, Bo Liu, Naiqing Zhang, Zafar Said, Sujan Debnath, Muhammad Jamil, Hafiz Muhammad Ali, Shubham, Sharma / The International Journal of Advanced Manufacturing Technology, No 117, P. 2565-2600, (2021), DOI: https://doi.org/10.1007/s00170-021-07854-1 .

13. Benedicto E. Technical, Economic and Environmental Review of the Lubrication/ Cooling Systems used in Machining Processes / E. Benedicto, D. Carou, E.M. Rubio / Procedia Engineering. (2017). Volume 184, P. 99 - 116, DOI: https://doi.org/10.1016/j.proeng.2017.04.075 .

14. Jalal Seyedmohammadi. The effects of drilling fluids and environment protection from pollutants using some models / Modeling Earth Systems and Environmwnt, 2017, No 3 (1). DOI: 10.1007/s40808-017-0299-7 .

15. Dianjie Sui1. Regulations and methods for disposal of waste drilling fluid / Dianjie Sui1, Mingwang Zhan, Dianxue Sui, Fulei Zhao / IOP Conference Series Earth and Environmental Science. No 631 (1):012045. DOI: http://dx.doi.org/10.1088/1755-1315/631/1/012045 .

16. Berezutskyi V.V. (2009). Ensuring safety in the application of water process emulsions and solutions in the production of metalworking technologies: Monograph. Kharkov: Fact, 400 p.

17. Kulsky L.A., Levchenko T.M, Petrova M.V. (1976). Chemistry and microbiology of water. Kiev: Vishcha schola, 115 p.

18. Monchenko E. (1974). Microbiology and hydrobiology of natural and waste waters. Novocherkassk, 201 p. 